\title{
When does word frequency influence written production?
}

\author{
Cristina Baus $^{1 *}{ }^{*}$, Kristof Strijkers ${ }^{2}$ and Albert Costa ${ }^{1,3}$ \\ ${ }^{1}$ Center for Brain and Cognition, Universitat Pompeu Fabra, Barcelona, Spain \\ ${ }^{2}$ Laboratoire de Psychology Cognitive, CNRS - Universite Aix-Marseille, Marseille, France \\ ${ }^{3}$ Institució Catalana de Recerca i Estudis Avançats, Barcelona, Spain
}

\section{Edited by:}

Marieke Longcamp, Aix-Marseille Univserity and CNRS, France

Reviewed by:

John P. Minda, The University of Western Ontario, Canada

Stephanie K. Ries, University of

California at Berkeley, USA

\section{*Correspondence:}

Cristina Baus, Department de Tecnología, Universitat Pompeu

Fabra, C/ Tànger, 122-140, 08018

Barcelona, Spain

e-mail: baus.cristina@gmail.com
The aim of the present study was to explore the central (e.g., lexical processing) and peripheral processes (motor preparation and execution) underlying word production during typewriting. To do so, we tested non-professional typers in a picture typing task while continuously recording EEG. Participants were instructed to write (by means of a standard keyboard) the corresponding name for a given picture. The lexical frequency of the words was manipulated: half of the picture names were of high-frequency while the remaining were of low-frequency. Different measures were obtained: (1) first keystroke latency and (2) keystroke latency of the subsequent letters and duration of the word. Moreover, ERPs locked to the onset of the picture presentation were analyzed to explore the temporal course of word frequency in typewriting. The results showed an effect of word frequency for the first keystroke latency but not for the duration of the word or the speed to which letter were typed (interstroke intervals). The electrophysiological results showed the expected ERP frequency effect at posterior sites: amplitudes for low-frequency words were more positive than those for high-frequency words. However, relative to previous evidence in the spoken modality, the frequency effect appeared in a later timewindow. These results demonstrate two marked differences in the processing dynamics underpinning typing compared to speaking: First, central processing dynamics between speaking and typing differ already in the manner that words are accessed; second, central processing differences in typing, unlike speaking, do not cascade to peripheral processes involved in response execution.

Keywords: written word production, typewriting, central and peripheral processes, lexical frequency

\section{INTRODUCTION}

In the last decades, typewriting (e.g., e-mailing, social networks) has become a fundamental tool for our personal and professional communication in daily life, especially in industrial societies. As a result, thousands of emails are written daily around the world. It is surprising then that despite the increasing relevance of such activity, relatively little is known about the underlying processes of writing in comparison to other means of communication (speaking). With the aim of extending our knowledge about written production, in the present study we explored the involvement of central and peripheral processes during single word (written) production.

Writing a word (as well as verbally producing it) requires the involvement of both central-cognitive and peripheral-motor processes (e.g., Margolin, 1984). Central processes, on the one hand, are those core linguistic processes that allow individuals to transform their ideas into the appropriate sequence of letters (or sounds) that compose the intended word. For that to be possible, information flows through different levels of processing: semantic, lexical (orthographic long term memory) and sublexical (orthographic working memory) (e.g., Hillis, 2008; Rapcsak et al., 2009). Indeed, response latencies, which are considered to reflect central processing, are sensitive to semantic, lexical, and orthographic manipulations (Bonin and Fayol, 2000, 2002; Bonin and Meot, 2002; Bonin et al., 2002, 2012). The peripheral processes, on the other hand, are those processes responsible for the engagement of the specific motor plans needed to execute the letters in the desired output modality (e.g., handwriting, typewriting) (see, Purcell et al., 2011). Response durations (and also interkeystroke intervals in typewriting) have been taken as reflecting operations at more peripheral levels of processing (e.g., Delattre et al., 2006).

Most of the work devoted to investigate written production (especially from the neuropsychological field; see Rapp and Dufor, 2011, for a review) has concerned two main issues: (1) whether information cascades within the central levels of processing similarly in speech and written production (e.g., Hillis et al., 1999), and (2) the relationship between the central and the peripheral processes underlying written production. Specifically, whether central and peripheral processes are staged and therefore independent from each other, or whether central processes cascade (influence) into peripheral processes. (Purcell et al., 2011; see for spoken production, Kello et al., 2000).

Our research aims to contribute to these two central issues in the field of written production by exploring: (1) the electrophysiological correlates of lexical processing within the central stages of typewriting, which will allow us to compare the temporal dynamics of written production with that in the spoken modality, and (2) whether lexical variables known to affect central stages during written production will also influence peripheral motor processes. Lexical frequency was manipulated as an index 
of lexical processing. As these two questions are relatively independent from each other, in the following we will first focus on the evidence regarding frequency effects within central-cognitive levels both in the written and the spoken modality, and then we will consider the evidence gathered so far regarding frequency effects at more peripheral-motor levels during writing.

Word frequency effects on response latencies have been extensively reported both in the writing and in the spoken modality. Words of high-frequency are written/named faster and more accurately than those of low-frequency (Bonin and Fayol, 2000, 2002; Caramazza and Costa, 2001; Caramazza et al., 2001; Roelofs, 2001; Bonin et al., 2002; Jescheniak et al., 2003; Navarrete et al., 2006; Kittredge et al., 2008; Strijkers et al., 2010). For those models assuming a lexical origin (Dell, 1986; Caramazza, 1997), the frequency effect has been taken as an index of the speed to which lexical representations are accessed. Indeed, electrophysiological, and intracranial studies have provided evidence of an early effect of frequency (Sahin et al., 2009; Strijkers et al., 2010). Around $200 \mathrm{~ms}$ after the picture onset presentation, ERP amplitudes corresponding to low-frequency words become more positive than those corresponding to high-frequency words $(\mathrm{P} 2)^{1}$. Note however, that this early ERP frequency effect does not exclude the possibility of frequency affecting later levels of processing, such as phonological encoding (Jescheniak and Levelt, 1994; Levelt et al., 1999; Almeida et al., 2007; Strijkers et al., 2010).

To the best of our knowledge, no study has explored the electrophysiological correlates of word frequency in typewriting. However, given that a priori there are no reasons to expect lexical effects to arise at different levels for writing and speaking (Perret and Laganaro, 2012; see also, Perret and Laganaro, 2013), frequency ERP effects are expected to arise in a similar time-window as the one observed in picture naming studies, around $200 \mathrm{~ms}$ (Strijkers et al., 2010). Moreover, in order to cover the potential effect of word frequency on later (post-lexical) central stages during written production (Perret and Laganaro, 2012), we also focused on later ERP components (e.g., P300).

Regarding word frequency effects at more peripheralexecution processes (e.g., Sternberg et al., 1978), the evidence is scarcer and the results on the influence of lexical frequency on response durations are quite mixed. Some studies have shown shorter writing durations or faster interkeystroke intervals for high-frequency words than for low-frequency ones (e.g., Gentner et al., 1988), which will favor the idea of cascade processing between central and peripheral levels during typewriting (e.g., Sahel et al., 2008). Others have shown no frequency effect on response durations (e.g., Delattre et al., 2006), supporting a more discrete processing (Logan and Zbrodoff, 1998; Damian and Freeman, 2008; Bonin et al., 2012). Thus, the evidence regarding the influence of central processes onto peripheral processes is far from conclusive. However, it should be noted that the different

\footnotetext{
${ }^{1}$ Besides word frequency, this early ERP effect has been demonstrated to be sensitive to a range of lexical phenomena, such as cognate-status (e.g., Strijkers et al., 2010), semantic interference (e.g., Costa et al., 2010) and response language (e.g., Strijkers et al., 2010, 2013) and therefore traced back to the onset of lexical access when preparing a word for speech (see Strijkers and Costa, 2011).
}

results come from different writing paradigms, which complicates to make generalizations regarding the stage/cascade nature of the underlying processes of written production. For instance, while frequency effects in response durations have been observed in a writing-to-copy task (e.g., transcribe an article; Gentner et al., 1988), no frequency effect was obtained in a writing-todictation task (Delattre et al., 2006). So, it is possible that the different demands imposed by the task vary the sensitivity of the peripheral processes to be influenced by the central ones (Delattre et al., 2006). In the present study we tested the frequency effects on response durations in a picture typewriting task, a task that has revealed frequency effects in the spoken modality $^{2}$. Therefore, if central and peripheral processes are closely interrelated as seems to be the case for spoken production, we predict shorter response durations and interstroke intervals for high compared to low-frequency picture names. In contrast, if written production is an activity where central processing has little or no effect on motor execution, both the response durations and the interstroke intervals should be unaffected by the word frequency manipulation.

In sum, in the present study we explored the temporal course of lexical access in typewriting, which will allow us to compare it with the speaking modality (e.g., Strijkers et al., 2010, 2011, 2013). The temporal precision of the ERPs will help us determine the exact moment/s in which word frequency affects written production. To do so, ERPs locked to the picture onset presentation were explored. Moreover, addressing the effect of word frequency in typewriting response durations will allow us to ask whether variables known to affect central processing activity (e.g., lexical access) will affect also response durations and interstroke intervals.

\section{METHODS}

\section{PARTICIPANTS}

Twenty Spanish native speakers (11 women) non-professional typers, from the University Pompeu Fabra took part in the experiment. All of them were right-handed, had normal or correctedto-normal vision and declared not having neurological or motor problems.

\section{MATERIALS}

Ninety-six black and white drawings were selected from the Snodgrass and Vanderwart (1980) and similar databases (Bates et al., 2003) (see Appendix for the full list of materials). Half of the pictures had high-frequency names and the remaining half had low-frequency names. Frequency values were larger for highfrequency (mean $=40.5, S D=41.7$ ) than for low-frequency words [mean $=4.7, S D=2.7 ; t_{(95)}=5.8, p<0.001$ ]. Words in both conditions were matched in letter length (HF mean: 6 letters, ranging from 4 to 10 letters long; LF: 5.6 letters, 4 to 9 letters long), neighborhood density and frequency of the first syllable (all $t \mathrm{~s}<$ 1). Importantly, high and low-frequency words were matched in

\footnotetext{
${ }^{2}$ In the spoken modality, there is convergent evidence showing shorter articulatory durations for high than for low-frequency words (Balota and Chumbley, 1990; Kawamoto et al., 1998; Kello et al., 2000; Damian et al., 2001; Kello, 2004; Gahl, 2008; but see, Wright, 1979; Meyer, 1991; Sadat et al., 2012).
} 
their first letter [e.g., bebé (HF, baby), bola (LF, ball)]. For all the pictures, name agreement ratings were collected. A new group of 24 participants was asked to provide a name for each picture. Name agreement was at $91 \%$ for pictures with high-frequency and $89 \%$ for those pictures with low-frequency names $(t<1)$.

\section{PROCEDURE}

Participants were instructed to type by means of a QWERTY standard keyboard the Spanish names of the pictures presented on the screen. The trial structure was as follows: (1) a fixation point appeared on the screen for $500 \mathrm{~ms}$, followed by the picture presentation for fixed time duration of $500 \mathrm{~ms}$. After that time the picture disappeared leaving a blank screen that remained until participants finished typing their response. Pictures were presented for a short and fixed time $(500 \mathrm{~ms})$, in order to avoid responses before the appearance of the blank screen. This was important given that as participants were allowed to look at the keyboard, movements would carry ocular artifacts in the ERPs. Nevertheless, as participants were non-professional typers and faster responses than $500 \mathrm{~ms}$ were not expected, participants were instructed to start typing their responses as soon as they knew the response (no response latency was below $500 \mathrm{~ms}$; see results section). Moreover, they could see and monitor their responses and were allowed to use the delete key whenever they made an error. When participants were confident with their response, they were instructed to press the Enter key for the next trial to start. The keyboard was located on the participants' laps, at enough distance $(\sim 60 \mathrm{~cm})$ from their eyes to avoid abrupt movements of the head when looking at the keyboard. The approximate distance between the participant and the center of the screen was $120 \mathrm{~cm}$. Participants were instructed to be still, not to move their head and look to the keyboard (moving only their eyes) as little as possible to avoid EOG artifacts. Reaction times were obtained for each keystroke. Words misspelled (even if self-corrected), or pictures for which the participant used a name different from the one designated by the experimenter were considered as errors and excluded from the analysis.

\section{EEG procedure and analysis}

The EEG was continuously recorded and linked-nose referenced from 30 scalp $\mathrm{Ag} / \mathrm{Cl}$ passive electrodes. Eye movements were monitored by two external electrodes placed horizontally (outer canthus) and vertically (below) to the right eye. Impedances were kept below $5 \mathrm{k} \Omega$. EEG signal was digitalized online with a $500 \mathrm{~Hz}$ sampling rate and a band pass filter of $0.1-125 \mathrm{~Hz}$. EEG data was filtered offline through a $0.03 \mathrm{~Hz}$ high-pass filter and $20 \mathrm{~Hz}$ low-pass filter and vertical and horizontal ocular artefacts were corrected (Gratton et al., 1983).

ERPs time locked to the onset of the stimulus were segmented into $750 \mathrm{~ms}$ epochs ( -200 to $550 \mathrm{~ms}$ ) and segments with incorrect responses, containing artefacts (brain activity above or below $100 \mu \mathrm{V}$ or a change in amplitude between adjacent segments of more than $200 \mu \mathrm{V}$ ) or eye blinks were excluded. The $750 \mathrm{~ms}$ epochs were then averaged in reference to $-200 \mathrm{~ms}$ pre-stimulus baseline.

Data analysis. We analyzed participants' behavioral and ERP responses. After excluding a participant with more than $25 \%$ of errors (one participant) the final analysis included 19 participants. Six words were also eliminated as having too many errors (more than 35\%) relative to the rest of the words (below 25\%). Behaviorally, three measures were obtained for correct responses: response latencies, response durations and interstroke intervals. Error rates were also analyzed.

ERP analysis. For the ERPs, we selected three time-windows of interest: the P2 time-window (170-230 ms), the N3 (230-330 ms) and the P3 (330-430 ms). A $2 \times 9 \times 3$ ANOVA was conducted considering Word frequency (high vs. low-frequency), Region of interest and Electrode [LeftAnterior (LA): F7, F3, FC5; Frontocentral (FC): Fz, FC1, FC2; RightAnterior (RA): F8, F4, FC6; Left-central (LC): T3, C3, CP5; Centro-Parietal (Cpar): CP1, Cp2, Pz; Right-central (RC): T4, C4, CP6; Left-parietal (LP): T5, P3, PO1; Right-parietal (RP): T6, P4, PO2; Occipital (O): O1, Oz, $\mathrm{O} 2]$. Moreover, the onset latency of the frequency effects was explored. ERPs for high and low-frequency words were compared by running a 2 -tailed paired $t$-test at every sampling point (every $2 \mathrm{~ms}$ ) starting from the picture presentation. The onset of the frequency effect was considered to be the first significant data point of a sequence of consecutive sampling points showing significant differences between high and low-frequency words ( $p$-values FDR corrected below 0.05; Benjamini and Hochberg, 1995).

\section{RESULTS \\ BEHAVIORAL \\ Response latencies}

Typing latencies and error rates were analyzed by means of separate $t$-test for participants and items in which high and low-frequency words were compared. We observed a significant frequency effect for typing latencies, $\left[t_{1(18)}=-2.8, p<0.05\right.$; $\left.t_{2(88)}=-1.9, p=0.05\right]$. Participants typed faster those pictures with high-frequency names (HF: 1398) than those with lowfrequency names (LF: 1483). Error rate analysis revealed no difference between high and low-frequency words (all $t \mathrm{~s}<1$ ).

\section{Response durations and interstroke interval}

Response durations, calculated as the difference between the onset of the word (first keystroke) and the offset of the word (last keystroke), tended to be shorter for high-frequency words (916 ms) than for low-frequency ones $(958 \mathrm{~ms})$ but this difference did not reach significance $\left[t_{1(18)}=1.5, p=0.1 ; t_{2}<1\right]$. Moreover, no differences were observed in the mean interstroke interval of high $(206 \mathrm{~ms})$ and low-frequency words (203 ms) $(t<1)$.

\section{ERPs}

A $2 \times 9 \times 3$ ANOVA considering Frequency, Region of interest (ROI) and electrode was explored in three time-windows: 170-230, 230-330, and 330-430 3 .

Table 1 shows the statistical analyses for each time-window. As indicated, frequency interacted with region at two time-windows. At the time-window between 230 and $330 \mathrm{~ms}$, the frequency

\footnotetext{
${ }^{3}$ In the $0-60$ time-window neither the frequency effect $\left[F_{(18)}=1.12\right.$, $p=0.30$, nor its interaction with region $(F<1)$ were significant.
} 
effect was only significant for those electrodes located at the LeftAnterior electrode cluster $\left[F_{(18)}=5.01, p=0.03\right]$. In this region, the frequency effect was in the opposite direction as expected; that is, ERP amplitudes for LF words were more negative than those for HF words. In contrast, in the time window between 330 and 430, ERP amplitudes for low-frequency words were significantly more positive than those of high-frequency at the posterior regions [PL: $F_{(18)}=4.3, p=0.05$; PC: $F_{(18)}=6.10$, $\left.p=0.02 ; \mathrm{O}: F_{(18)}=6.19, p=0.02\right]$ (see Figures 1, 2).

Table 1 | Statistics resulting from the ANOVAs conducted at each temporal window.

\begin{tabular}{llll}
\hline & $\mathbf{1 7 0 - 2 3 0}$ & $\mathbf{2 3 0 - 3 3 0}$ & $\mathbf{3 3 0 - 4 3 0}$ \\
\hline Frequency & $F<1$ & $F<1$ & $\begin{array}{l}F_{(1,18)}=3.3, \\
p=0.08\end{array}$ \\
\hline Region & $\begin{array}{l}F_{(1.5,28.4)}=2.1, \\
p=0.14\end{array}$ & $\begin{array}{l}\boldsymbol{F}_{(\mathbf{1 . 7}, \mathbf{3 1 . 1})}=\mathbf{1 9 . 9}, \\
\boldsymbol{p}=\mathbf{0 . 0 0 0}\end{array}$ & $\begin{array}{l}\boldsymbol{F}_{(\mathbf{1 . 7}, \mathbf{3 1 . 1})}=\mathbf{1 1 . 3}, \\
\boldsymbol{p}=\mathbf{0 . 0 0 0}\end{array}$ \\
\hline $\begin{array}{l}\text { Frequency } * \\
\text { Region }\end{array}$ & $F<1$ & $\begin{array}{l}\boldsymbol{F}_{(\mathbf{2 . 1}, \mathbf{3 8 . 9})}=\mathbf{3 . 1}, \\
\boldsymbol{p}=\mathbf{0 . 0 5}\end{array}$ & $\begin{array}{l}\boldsymbol{F}_{(\mathbf{2}, \mathbf{3 6 . 6})}=\mathbf{3 . 8}, \\
\boldsymbol{p}=\mathbf{0 . 0 2}\end{array}$ \\
\hline $\begin{array}{l}\text { Frequency } * \\
\text { Region } *\end{array}$ & $F<1$ & $F<1$ & $\begin{array}{l}F_{(3.2,58.3)}=1.7, \\
p=0.17\end{array}$
\end{tabular}

\section{Onset latency analysis}

Given the observed ERP frequency effect was maximal over posterior electrodes, onset latency analyses were based only on the mean amplitude of the nine electrodes located at posterior regions (T5, P3, PO1, PO2, P4, T6, O1, Oz, O2). The latency analysis revealed that ERP amplitudes for low and high-frequency

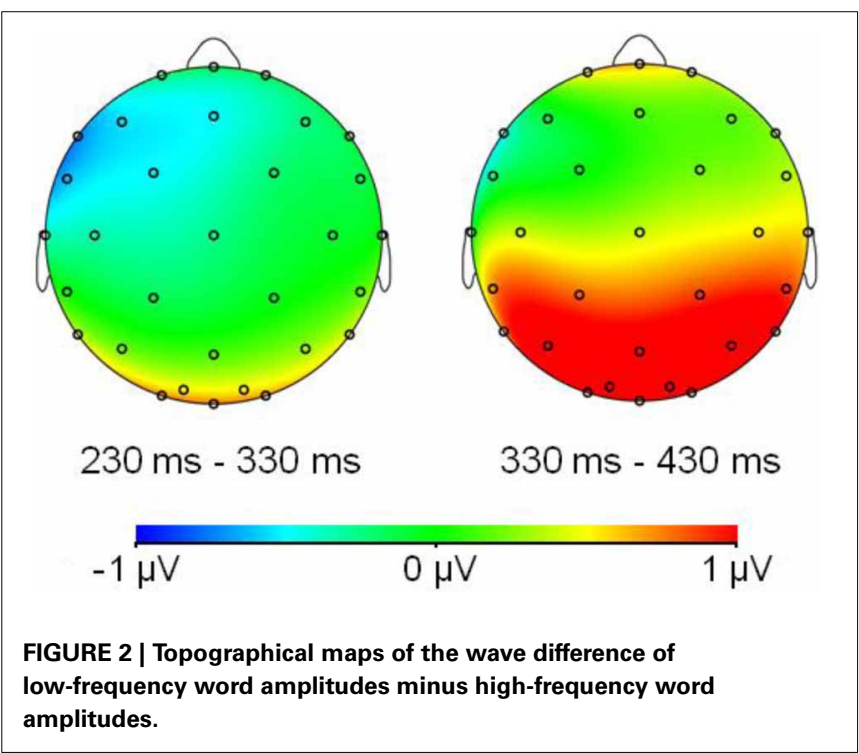

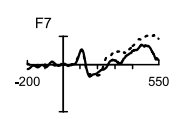
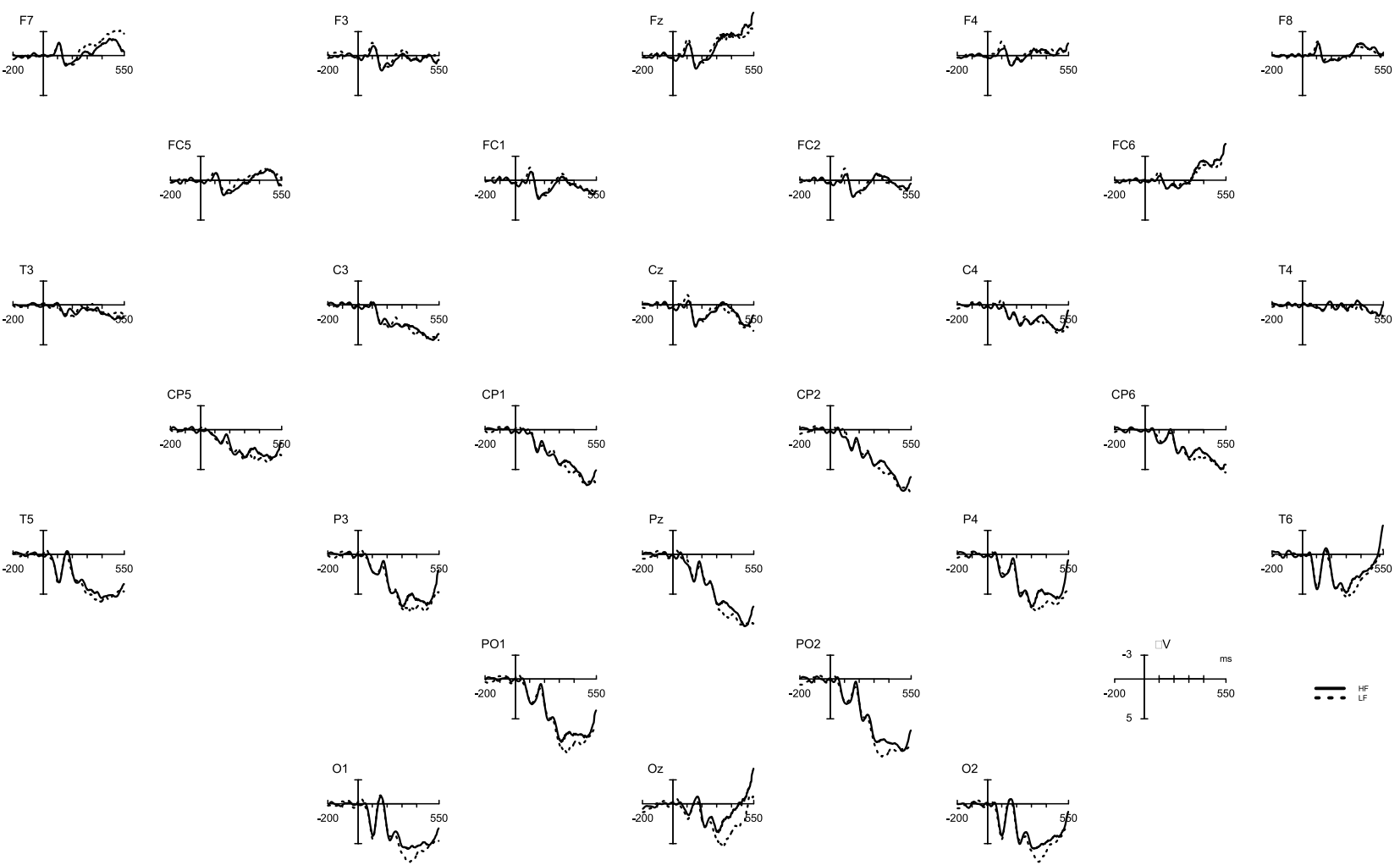
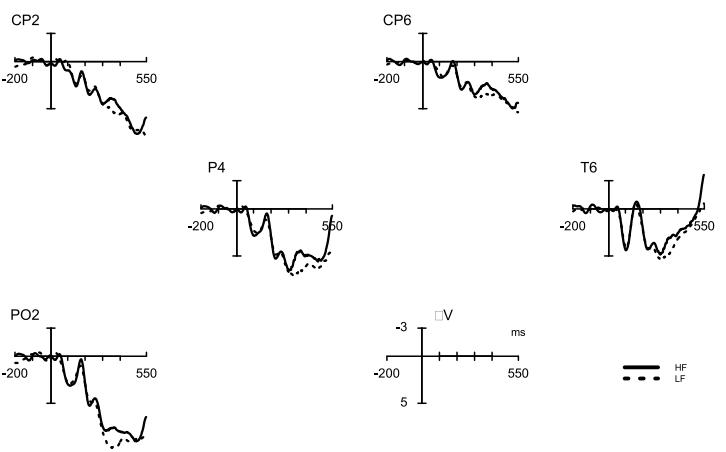

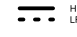

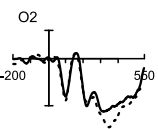

FIGURE 1 | ERP waveforms for high (solid line) and low-frequency words (dashed line) locked to the onset of the picture presentation. 
words started to diverge significantly at $324 \mathrm{~ms}$ after picture onset presentation and the difference remained until $396 \mathrm{~ms}$ after the picture onset ( $p$-values FDR corrected below 0.05) (see Figure 3).

\section{DISCUSSION}

The aim of the present study was to investigate: (1) the temporal course of lexical access in typewriting, and (2) the discrete/cascade relationship between central and peripheral processes during written word production. By means of a picture typewriting task, we explored the influence of word frequency within the central levels of processing, and whether its influence extends also to peripheral-motor levels of processing. Our results revealed that low-frequency words elicited longer typing latencies and larger amplitudes than high-frequency words. Moreover, the ERP results revealed a frequency effect arising around $350 \mathrm{~ms}$ after the picture onset. In contrast, no frequency effect was observed during typing execution: frequency did not influence the duration of the words nor the speed to which the letters composing a given word were typed.

Regarding the influence of lexical frequency within central processes, our results replicate previous findings on the effects of word frequency (e.g., Bonin and Fayol, 2002): High-frequency words are produced faster than low-frequency ones and this occurs regardless of the modality in which the word will be finally produced (written production or speech production). Moreover, low-frequency words elicited more positive amplitudes than those elicited by high-frequency words, replicating the ERP frequency effect observed in the spoken modality (Strijkers et al., 2010, 2011). However, and in contrast to the posterior frequency effect (posterior P2) in the picture naming (e.g., Strijkers et al., 2010), the frequency effect in typing became apparent later in time: high and low-frequency words differed at the time-window between 330 and $430 \mathrm{~ms}$. As we will comment below, the posterior frequency effect was accompanied by an anterior frequency effect with low-frequency words eliciting more negative amplitudes than high-frequency ones.

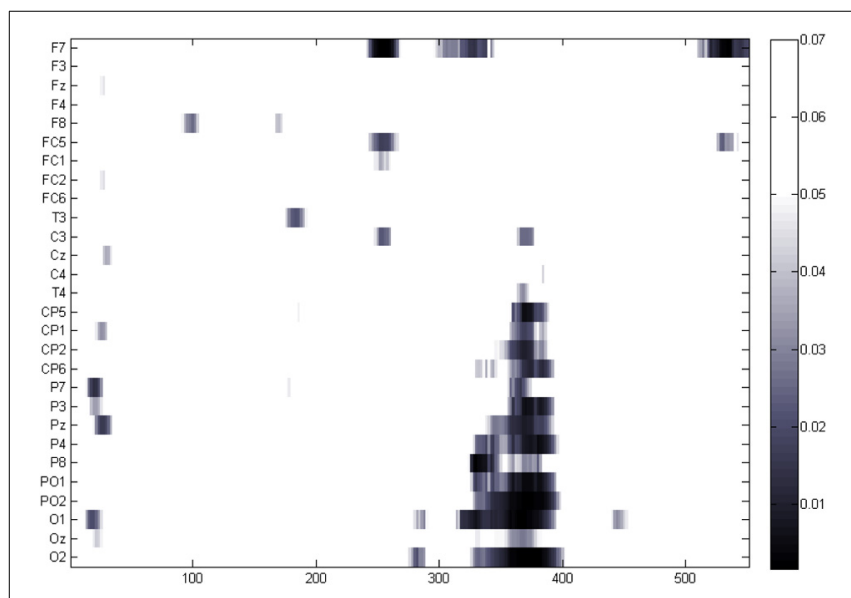

FIGURE $3 \mid \boldsymbol{P}$-values resulting from the paired $\boldsymbol{t}$-test (FDR corrected) at each sampling point. Colored points correspond to those $p$-values below 0.05 .
Why does the posterior lexical frequency effect manifests earlier in speech production than in typewriting? One possibility is that word frequency only affects post-lexical processes in typing while it already modulates initial lexical access in speaking. Indeed, based on the temporal meta-analysis of speech production provided by Indefrey and Levelt (2004), effects after $300 \mathrm{~ms}$ are thought to index sublexical processing (phonology/orthography). However, such strategy for assigning levels of representation to time-course is highly tentative (more so since Indefrey and Levelt's estimates are based on an average response latency of only $600 \mathrm{~ms}$ ) and speculative at best (Strijkers and Costa, 2011). This is especially so when taking into account that it is well documented by now that word frequency is an ubiquitous variable affecting both early and late stages of central processing (e.g., Almeida et al., 2007; Graves et al., 2007; Knobel et al., 2008; Strijkers et al., 2010).

Alternatively, it might be possible that the observed delay in the ERP frequency effects is the result of an overall slow-down of the response latencies (around $1400 \mathrm{~ms}$ ) relative to the spoken modality (around $700 \mathrm{~ms}$ ). However, and contrasting this position, other word production studies have shown that the onset of lexical access seems unaffected by the speed of the response. For instance, in three ERP studies of overt naming (Strijkers et al., 2010, 2011, 2013; see also Laganaro et al., 2012) reaction times fluctuated roughly between 600 and $1000 \mathrm{~ms}$, but the onset of the lexical frequency effect remained constant. The latter makes sense since it indicates that the reaction times in naming are influenced by linguistic factors only after initiating lexical selection and not before at pre-linguistic stages of processing, consistent with the predictions of the dominant speech production models (e.g., Dell, 1986; Caramazza, 1997; Levelt et al., 1999). In a similar vein, it seems unlikely to conclude from these findings that picture recognition - the required step prior to engaging the language system-is slower in typing than in speaking. However, what might be different between both production types is the speed with which picture semantics can access words. That is, while we do have daily experience with naming visual information in our environment (e.g., Pass me that bottle. Is that chair taken? You look sad), the same is not true for typing. Therefore, connections from picture semantics with those linguistic representations relevant for speech production (e.g., lexical phonology) could be more strongly linked in the brain than those from picture semantics to representations involved for typing (e.g., orthography), and therefore the latter are accessed in a less automatized and consequently, slower manner. Note that at the core of this assumption lies the idea that the way in which words are accessed from perceived objects is different depending on the type of production task engaged, consistent with the notion that the earliest linguistic modulations are driven (in part) by specific top-down modulations preparing those brain systems and neural pathways relevant to the goal-directed behavior at hand (e.g., Strijkers et al., 2011). Based on the current data we cannot determine whether this explanation is indeed behind the observed pattern, but it certainly involves an excellent question for future research. For now, the important contribution here is the demonstration that the brain's response to word frequency is different between speaking and typing. This finding is at odds with previous claims in the literature 
that lexical processing is fully shared between the two production modalities (e.g., Perret and Laganaro, 2012, 2013).

To conclude this section, we must comment on the reversed frequency effect at the anterior sites preceding the posterior frequency effect: Between 230 and $330 \mathrm{~ms}$ after picture onset lowfrequency amplitudes were more negative than high-frequency ones. A similar result was found in a recent study of overt object naming (Strijkers et al., 2013), the only difference between these two studies being the presence of the posterior P2 frequency effect in the latter study (i.e., spoken modality). The authors tentatively proposed this N300 effect could be related to integration of object semantics as encountered in picture processing tasks (e.g., Holcomb and McPherson, 1994; McPherson and Holcomb, 1999; Schendan and Kutas, 2002; West and Holcomb, 2002; Schendan and Maher, 2008). Another possibility is that this negative deflection is associated with cognitive control indexed by the N2 component (Falkenstein et al., 1999; Nieuwenhuis et al., 2003; Folstein and Van Petten, 2008), especially since in language it seems to manifest slightly later in time, peaking around $300 \mathrm{~ms}$ after picture onset (e.g., Jackson et al., 2001; Swainson et al., 2003; Christoffels et al., 2007; Verhoef et al., 2009; Martin et al., 2013), with items of low-frequency requiring an increase in cognitive control compared to the high-frequency ones. Nevertheless, whether the current negative anterior ERP effect can be seen as functionally related to those encountered in conceptual processing of object knowledge or recruitment of cognitive control has yet to be established, given that componentry comparisons over very different tasks is difficult (e.g., Picton et al., 2000). However, one may still argue that the language-related frequency effects in the typewriting task are characterized by an anterior negativity rather than by the later posterior positivity. This option seems unlikely, however, given that the anterior effect was very small (it did not survive our correction for multiple comparisons in the onset latency analyses) and localized to only a few scalp electrodes. This indicates a very fine-grained effect generated by a small population of synchronously firing neurons, while a variable as word frequency is known to produce robust and extended ERP modulations in production tasks (e.g., Fiez et al., 1999; Graves et al., 2007; Strijkers et al., 2010, 2011, 2013). With this finding and given the fact that the earliest effects of lexical frequency consistently elicit modulations at posterior sites in both language production and perception (e.g., Hauk and Pulvermüller, 2004; Hauk et al., 2006; Strijkers et al., 2010, 2011, 2013), we maintain that the first modulations of word frequency within the language system are engendered by the posterior positivity between 330 and $430 \mathrm{~ms}$. However, even if we take on the unlikely stance that in typewriting the first language-sensitive modulations of word frequency are reflected in the anterior negativity, that does not compromise our conclusion with respect to the temporal dissociation in lexical access between speaking and writing given that the N300 modulation still occurs about $100 \mathrm{~ms}$ later compared to the $\mathrm{P} 2$ effects in object naming (more so, it would indicate that not only the time-course but also the neural generators-anterior in case and posterior in the other-are functionally distinct between the two production modalities).

Regarding the second main question we wanted to address in this study, namely whether lexical variables influence the execution of peripheral-motor commands in typewriting, our results did not show frequency effects during response execution, neither in the duration of the word, nor in the speed with which letters were typed. This result is at odds with previous evidence in the spoken and writing modalities showing a negative correlation between the frequency of the word and its articulatory duration (e.g., Gentner et al., 1988; Balota and Chumbley, 1990). In contrast, it favors those proposals assuming that in writing, information flows from central to peripheral processes in a discrete manner (e.g., Damian and Freeman, 2008). That is, central and peripheral processes underlying typewriting are independent from each other. Hence, the influence of lexical variables on the speed with which a word is selected does not extend to the motor commands involved in executing the production of that word ${ }^{4}$. Similarly, the evidence coming from different cases of dysgraphia also supports a clear distinction between central and peripheral processes. Peripheral dysgraphias, are characterized for instance by the repetition, omission, and substitution of letters while writing, but the pattern of writing is not affected by lexical variables such as length, frequency or word class (e.g., Ellis, 1988; Papagno, 1992).

The dissociation between typewriting and speech production, regarding the influence of central processes on peripheral ones is noteworthy. At first glance, it seems counterintuitive that for one type of production behavior differences during central processing cascade to peripheral processing while for another type of production behavior they do not. However, just as argued for the observed differences between speaking and typing with respect to central processing, this could be related to a difference in "proficiency" between both skills. While we engage in speech acts continuously, the amount of typing we perform daily will be much lower for most people. Hence, an interesting (and perhaps even domain-general) question which surfaces from our study is whether the amount of cascading is (among other factors) dependent on the amount of automaticity and attention underlying a particular skill. In this manner, during speech production there may be sufficient "room" to optimize processing through cascading and already engage in motor execution prior to the completion of speech planning. In contrast, for those with less practice at typing, cascading between planning and execution might be more limited because of the higher processing demands on both central processes for retrieving the correct graphemic information and on peripheral factors, such as the frequency of diagraphs or the physical difficulty of the typing movement (two hands vs. one hand; Gentner et al., 1988). It will be very interesting to see in future research whether for more experienced typers (e.g., clerks, scientists, etc.) or for a more frequently used form of typing (text messaging on mobile phone), central processing will demonstrate earlier lexical effects as well as cascading between central and peripheral processes, just as encountered for its spoken counterpart.

\footnotetext{
${ }^{4}$ For typewriting models, such as the Activation-Trigger-Schemata, proposed by Rumelhart and Norman (1982), the lack of frequency effects in typing could be explained as a result of the sequential activation of the motor
} commands of the letters composing a word. 
In sum, our data demonstrated two marked differences for typewriting compared to speech production: First, lexical access is delayed by some $200 \mathrm{~ms}$ for typewriting compared to speaking. Second, while in speech production processing differences arising at the level of planning can affect later execution, in typewriting central and peripheral processes seem relatively independent from each other. These results document that speaking and typing do not just differ with respect to their output modality, but also with respect to the processing dynamics underpinning both types of production behavior. We tentatively suggest that these processing differences might be caused by differences in the amount of automaticity and attention required for performing a speech vs. type act.

\section{ACKNOWLEDGMENTS}

This research was supported by two grants from the Spanish Government PSI2008-01091 and CONSOLIDER-INGENIO2010 CSD2007-00048 and one grant from the Catalan Government SGR 2009-1521. Cristina Baus was supported by a post-doctoral fellowship JCI-2010-06504 from the Spanish Government. Kristof Strijkers was supported by the Intra-European Fellowship (FP7-PEOPLE-2012-IEF) of the Marie Curie Actions.

\section{REFERENCES}

Almeida, J., Knobel, M., Finkbeiner, M., and Caramazza, A. (2007). The locus of the frequency effect in picture naming: when recognizing is not enough. Psychon. Bull. Rev. 14, 1177-1182. doi: 10.3758/BF03193109

Balota, D. A., and Chumbley, J. I. (1990). Where are the effects of frequency in visual word recognition tasks? Right where we said they were! Comment on Monsell, Doyle, and Haggard (1989), J. Exp. Psychol. Gen. 119, 231-237. doi: 10.1037/0096-3445.119.2.231

Bates, E., D’Amico, S., Jacobsen, T., Székely, A., Andonova, E., Devescovi, A., et al. (2003). Timed picture naming in seven languages. Psychon. Bull. Rev. 10, 344-380. doi: 10.3758/BF03196494

Benjamini, Y., and Hochberg, Y. (1995). Controlling the False Discovery Rate: a practical and powerful approach to multiple testing. J. R. Stat. Soc. 57, 289-300.

Bonin, P., Chalard, M., Méot, A., and Fayol, M. (2002). The determinants of spoken and written picture naming latencies. Br. J. Psychol. 93, 89-114. doi: $10.1348 / 000712602162463$

Bonin, P., and Fayol, M. (2000). Writing words from pictures: what representations are activated, and when? Mem. Cogn. 28, 677-689. doi: 10.3758/ BF03201257

Bonin, P., and Fayol, M. (2002). Frequency effects in the written and spoken production of homophonic picture names. Eur. J. Cogn. Psychol. 14, 289-313. doi: 10.1080/09541440143000078

Bonin, P., and Meot, A. (2002). "Writing to dictation in real time in adults: what are the determinants of written latencies," in Advances in Psychology research, Vol. 16, ed S. P. Shohov (New York, NY: Nova Science Publishers).

Bonin, P., Roux, S., Barry, C., and Canell, L. (2012). Evidence for a limitedcascading account of written word naming. J. Exp. Psychol. Learn. Mem. Cogn. 38, 1741-1758. doi: 10.1037/a0028471

Caramazza, A. (1997). How many levels of processing are there in lexical access? Cogn. Neuropsychol. 14, 177-208. doi: 10.1080/026432997381664

Caramazza, A., Costa, A., Miozzo, M., and Bi, Y. (2001). The specific-word frequency effect: implications for the representation of homophones in speech production. J. Exp. Psychol. Learn. Mem. Cogn. 27, 1430-1450. doi: 10.1037/02787393.27.6.1430

Caramazza, A., and Costa, A. (2001). Set size and repetition in the pictureword interference paradigm: implications for models of naming. Cognition 80, 291-298. doi: 10.1016/S0010-0277(00)00137-2

Christoffels, I. K., Firk, C., and Schiller, N. O. (2007). Bilingual language control: an event-related brain potential study. Brain Res. 1147, 192-208. doi: 10.1016/j.brainres.2007.01.137
Costa, A., Strijkers, K., Martin, C., and Thierry, G. (2010). The time course of word retrieval revealed by event-related brain potentials during overt speech. Proc. Natl. Acad. Sci. 106, 21442-21446. doi: 10.1073/pnas.0908921106

Damian, M. F., and Freeman, N. H. (2008). Flexible and inflexible response components: a stroop study with typewritten output. Acta Psychol. 128, 91-101. doi: 10.1016/j.actpsy.2007.10.002

Damian, M. F., Vigliocco, G., and Levelt, W. J. M. (2001). Effects of semantic context in the naming of pictures and words. Cognition 81, B77-B86. doi: 10.1016/S0010-0277(01)00135-4

Delattre, M., Bonin, P., and Barry, C. (2006). Written spelling to dictation: soundto-spelling regularity affects both writing latencies and durations. J. Exp. Psychol. Learn. Mem. Cogn. 32, 1330-1340. doi: 10.1037/0278-7393.32.6.1330

Dell, G. S. (1986). A spreading activation theory of retrieval in language production. Psychol. Rev. 93, 283-321. doi: 10.1037/0033-295X.93.3.283

Ellis, A. W. (1988). Normal writing processes and peripheral acquired dysgraphias. Lang. Cogn. Proces. 3, 99-127. doi: 10.1080/01690968808402084

Falkenstein, M., Hoormann, J., and Hohnsbein, J. (1999). ERP components in Go/Nogo tasks and their relation to inhibition. Acta Psychol. 101, 267-291. doi: 10.1016/S0001-6918(99)00008-6

Fiez, J. A., Balota, D. A., Raichle, M. E., and Petersen, S. E. (1999). Effects of lexicality, frequency and spelling-to-sound consistency on the functional anatomy of reading. Neuron 24, 205-218. doi: 10.1016/S0896-6273(00)80833-8

Folstein, J. R., and Van Petten, C. (2008). Influence of cognitive control and mismatch on the N2 component of the ERP: a review. Psychophysiology 45, 152-170. doi: 10.1111/j.1469-8986.2007.00602.x

Gahl, S. (2008). Time and thyme are not homophones: the effect of lemma frequency on word durations in spontaneous speech. Language 84, 474-496. doi: 10.1353/lan.0.0035

Gentner, D. R., Larochelle, S., and Grudin, J. (1988). Lexical, sublexical, and peripheral effects in skilled typewriting. Cogn. Psychol. 20, 524-548. doi: 10.1016/0010-0285(88)90015-1

Gratton, G., Coles, M. G. H., and Donchin, E. (1983). A new method for off-line removal of ocular artifact. Electroencephalogr. Clin. Neurophysiol. 55, 468-484. doi: 10.1016/0013-4694(83)90135-9

Graves, W. W., Grabowski, T. J., Mehta, S., and Gordon, J. K. (2007). A neural signature of phonological access: distinguishing the effects of word frequency from familiarity and length in overt picture naming. J. Cogn. Neurosci. 19, 617-631. doi: 10.1162/jocn.2007.19.4.617

Hauk, O., Davis, M. H., Ford, M., Pulvermüller, F., and Marslen-Wilson, W. (2006). The time course of visual word-recognition as revealed by linear regression analysis of ERP data. Neuroimage 30, 1383-1400. doi: 10.1016/j.neuroimage.2005.11.048

Hauk, O., and Pulvermüller, F. (2004). Effects of word length and frequency on the human ERP. Clin. Neurophysiol. 115, 1090-1103. doi: 10.1016/j.clinph.2003.12.020

Hillis, A. E. (2008). Cognitive processes underlying reading and writing and their neural substrates. Handb. Clin. Neurol. 88, 311-322. doi: 10.1016/S00729752(07)88015-8

Hillis, A. E., Rapp, B. C., and Caramazza, A. (1999). When a rose is a rose in speech but a tulip in writing. Cortex $35,337-356$. doi: 10.1016/S0010-9452(08) 70804-9

Holcomb, P. J., and McPherson, W. B. (1994). Event-related brain potentials reflect semantic priming in an object decision task. Brain Cogn. 24, 259-276. doi: 10.1006/brcg.1994.1014

Indefrey, P., and Levelt, W. J. M. (2004). The spatial and temporal signatures of word production components. Cognition 92, 101-144. doi: 10.1016/j.cognition.2002.06.001

Jackson, G. M., Swainson, R., Cunnington, R., and Jackson, S. R. (2001). ERP correlates of executive control during repeated language switching. Bilingualism Lang. Cogn. 4, 169-178. doi: 10.1017/S1366728901000268

Jescheniak, J. D., and Levelt, W. J. M. (1994). Word frequency effects in speech production: retrieval of syntactic information and of phonological form. J. Exp. Psychol. Learn. Mem. Cogn. 20, 824-843. doi: 10.1037/0278-7393. 20.4.824

Jescheniak, J. D., Meyer, A. S., and Levelt, W. J. M. (2003). Specific-word frequency is not all that counts in speech production: comments on Caramazza, Costa, et al. (2001) and new experimental data. J. Exp. Psychol. Learn. Mem. Cogn. 29, 432-438. doi: 10.1037/0278-7393.29.3.432

Kawamoto, A. H., Kello, C. T., Jones, R., and Bame, K. (1998). Initial phoneme versus whole-word criterion to initiate pronunciation: evidence based on response 
latency and initial phoneme duration. J. Exp. Psychol. Learn. Mem. Cogn. 24:862. doi: 10.1037/0278-7393.24.4.862

Kello, C. T. (2004). Control over the time course of cognition in the temponaming task. J. Exp. Psychol. Hum. Percept. Perform. 30, 942. doi: 10.1037/00961523.30.5.942

Kello, C. T., Plaut, D. C., and MacWhinney, B. (2000). The task dependence of staged versus cascaded processing: an empirical and computational study of stroop interference in speech perception. J. Exp. Psychol. Gen. 129, 340. doi: 10.1037/0096-3445.129.3.340

Kittredge, A. K., Dell, G. S., Verkuilen, J., and Schwartz, M. F. (2008). Where is the effect of frequency in word production? insights from aphasic picture-naming errors. Cogn. Neuropsychol. 25, 463-492. doi: 10.1080/02643290701674851

Knobel, M., Finkbeiner, M., and Caramazza, A. (2008). The many places of frequency: evidence for a novel locus of the lexical frequency effect in word production. Cogn. Neuropsychol. 25, 256-286. doi: 10.1080/0264329070 1502425

Laganaro, M., Valente, A., and Perret, C. (2012). Time course of word production in fast and slow speakers: a high density ERP topographic study. Neuroimage 9 , 3881-3888. doi: 10.1016/j.neuroimage.2011.10.082

Levelt, W. J. M., Roelofs, A., and Meyer, A. S. (1999). A theory of lexical access in speech production. Behav. Brain Sci. 22, 1-38. doi: 10.1017/S0140525X99001776

Logan, G. D., and Zbrodoff, N. J. (1998). Stroop-type interference: congruity effects in color naming with typewritten responses. J. Exp. Psychol. Hum. Percep. Perform. 24, 978-992. doi: 10.1037/0096-1523.24.3.978

Margolin, D. I. (1984). The neuropsychology of writing and spelling: semantic, phonological, motor, and perceptual processes. Q. J. Exp. Psychol. 36, 459-489. doi: 10.1080/14640748408402172

Martin, C. D., Strijkers, K., Santesteban, M., Escera, C., Hartsuiker, R. J., and Costa, A. (2013). The impact of early bilingualism on controlling a language learned late: An ERP study. Front. Psychol. 4:815. doi: 10.3389/fpsyg. 2013.00815

McPherson, W. B., and Holcomb, P. J. (1999). An electrophysiological investigation of semantic priming with pictures of real objects. Psychophysiology 36, 53-65. doi: $10.1017 /$ S0048577299971196

Meyer, A. S. (1991). The time course of phonological encoding in language production: phonological encoding inside a syllable. J. Mem. Lang. 30, 69-89. doi: 10.1016/0749-596X(91)90011-8

Navarrete, E., Basagni, B., Alario, F. X., and Costa, A. (2006). Does word frequency affect lexical selection in speech production? Q. J. Exp. Psychol. 59, 1681-1690. doi: 10.1080/17470210600750558

Nieuwenhuis, S., Yeung, N., van den Wildenberg, W., and Ridderinkhof, K. R. (2003). Electrophysiological correlates of anterior cingulate function in a go/nogo task: effects of response conflict and trial type frequency. Cogn. Affect. Behav. Neurosci. 3, 17-26. doi: 10.3758/CABN.3.1.17

Papagno, C. (1992). A case of peripheral dysgraphia. Cogn. Neuropsychol. 9, 259-270. doi: 10.1080/02643299208252061

Perret, C., and Laganaro, M. (2012). Comparison of electrophysiological correlates of writing and speaking: a topographic ERP analysis. Brain Topogr. 25, 64-72. doi: 10.1007/s10548-011-0200-3

Perret, C., and Laganaro, M. (2013). Why are written picture naming latencies (not) longer than spoken naming? Read. Writ. 26, 225-239. doi: 10.1007/s11145-0129365-8

Picton, T. W., Bentin, S., Berg, P., Donchin, E., Hillyard, S. A., Johnson, Jr, R., et al. (2000). Guidelines for using human event-related potentials to study cognition: recording standards and publication criteria. Psychophysiology, 37, 127-152. doi: 10.1111/1469-8986.3720127

Purcell, J. J., Turkeltaub, P. E., Eden, G. F., and Rapp, B. (2011). Examining the central and peripheral processes of written word production through meta-analysis. Front. Psychol. 2:239. doi: 10.3389/fpsyg.2011.00239

Rapcsak, S. Z., Beeson, P. M., Henry, M. L., Leyden, A., Kim, E., Rising, K., et al. (2009). Phonological dyslexia and dysgraphia: cognitive mechanisms and neural substrates. Cortex 45, 575-591. doi: 10.1016/j.cortex.2008.04.006

Rapp, B., and Dufor, O. (2011). The neurotopography of written word production: An fMRI investigation of the distribution of sensitivity to length and frequency. J. Cogn. Neurosci. 23, 4067-4081. doi: 10.1162/jocn_ a_00109

Roelofs, A. (2001). Set size and repetition matter: comment on Caramazza and Costa (2000). Cognition 80, 283-290. doi: 10.1016/S0010-0277(01)00134-2
Rumelhart, D. E., and Norman, D. A. (1982). Simulating a skilled typist: a study of skilled cognitive-motor performance. Cogn. Sci. 6, 1-36. doi: $10.1207 / \mathrm{s} 15516709 \operatorname{cog} 0601 \_1$

Sadat, J., Martin, C. D., Alario, F. X., and Costa, A. (2012). Characterizing the bilingual disadvantage in noun-phrase production. J. Psycholinguist. Res. 41, 159-179. doi: 10.1007/s10936-011-9183-1

Sahel, S., Nottbusch, G., Grimm, A., and Weingarten, R. (2008). Written production of German compounds: effects of lexical frequency and semantic transparency. Writ. Lang. Lit. 11, 211-227. doi: 10.1075/wll.11.2.06sah

Sahin, N. T., Pinker, S., Cash, S. S., Schomer, D., and Halgren, E. (2009). Sequential processing of lexical, grammatical, and phonological information within broca's area. Science 326, 445-449. doi: 10.1126/science.1174481

Schendan, H. E., and Kutas, M. (2002). Neurophysiological evidence for two processing times for visual object identification. Neuropsychologia 40, 931-945. doi: 10.1016/S0028-3932(01)00176-2

Schendan, H. E., and Maher, S. M., (2008). Object knowledge during entry-level categorization is activated and modified by implicit memory after $200 \mathrm{~ms}$. Neuroimage, 44, 1423-1438. doi: 10.1016/j.neuroimage.2008.09.061

Snodgrass, J. G., and Vanderwart, M. (1980). A standardized set of 260 pictures: norms for name agreement, familiarity and visual complexity. J. Exp. Psychol. Hum. Learn. Mem. 6, 174-215. doi: 10.1037/0278-7393.6.2.174

Sternberg, S., Monsell, S., Knoll, R. L., and Wright, C. E. (1978). "The latency and duration of rapid movement sequences: comparisons of speech and typewriting," in Information Processing in Motor Control and Learning, ed G. E. Stelmach (New York, NY: Academic Press), 117-152.

Strijkers, K., Baus, C., Runnqvist, E., Fitzpatrick, I., and Costa, A. (2013). The temporal dynamics of first versus second language production. Brain Lang. 127, 6-11. doi: 10.1016/j.bandl.2013.07.008

Strijkers, K., and Costa, A. (2011). Riding the lexical speedway: a critical review on the time course of lexical selection in speech production. Front. Psychol. 2:356. doi: 10.3389/fpsyg.2011.00356

Strijkers, K., Costa, A., and Thierry, G. (2010). Tracking lexical access in speech production: electrophysiological correlates of word frequency and cognate effects. Cereb. Cortex 20, 912-928. doi: 10.1093/cercor/bhp153

Strijkers, K., Holcomb, P. J., and Costa, A. (2011). Conscious intention to speak proactively facilitates lexical access during overt object naming. J. Mem. Lang. 65, 345-362. doi: 10.1016/j.jml.2011.06.002

Swainson, R., Cunnington, R., Jackson, G. M., Rorden, C., Peters, A. M., Morris, P. G., et al. (2003). Cognitive control mechanisms revealed by ERP and fMRI: evidence from repeated task-switching. J. Cogn. Neurosci. 15, 785-799. doi: 10.1162/089892903322370717

Verhoef, K., Roelofs, A., and Chwilla, D. J. (2009). Role of inhibition in language switching: evidence from event-related brain potentials in overt picture naming. Cognition 110, 84-99. doi: 10.1016/j.cognition.2008.10.013

West, W. C., and Holcomb, P. J. (2002). Event-related potentials during discourselevel semantic integration of complex pictures. Cogn. Brain Res. 13, 363-375. doi: 10.1016/S0926-6410(01)00129-X

Wright, C. E. (1979). Duration differences between rare and common words and their implications for the interpretation of word frequency effects. Mem. Cogn. 7, 411-419. doi: 10.3758/BF03198257

Conflict of Interest Statement: The authors declare that the research was conducted in the absence of any commercial or financial relationships that could be construed as a potential conflict of interest.

Received: 15 July 2013; accepted: 06 December 2013; published online: 24 December 2013.

Citation: Baus C, Strijkers K and Costa A (2013) When does word frequency influence written production?. Front. Psychol. 4:963. doi: 10.3389/fpsyg.2013.00963

This article was submitted to Cognitive Science, a section of the journal Frontiers in Psychology.

Copyright (c) 2013 Baus, Strijkers and Costa. This is an open-access article distributed under the terms of the Creative Commons Attribution License (CC BY). The use, distribution or reproduction in other forums is permitted, provided the original author(s) or licensor are credited and that the original publication in this journal is cited, in accordance with accepted academic practice. No use, distribution or reproduction is permitted which does not comply with these terms. 


\section{APPENDIX}

Table A1 | Full list of materials.

\begin{tabular}{|c|c|c|c|}
\hline \multicolumn{2}{|c|}{ High-frequency words } & \multicolumn{2}{|c|}{ Low-frequency words } \\
\hline $\begin{array}{l}\text { Spanish } \\
\text { names }\end{array}$ & $\begin{array}{l}\text { English } \\
\text { translation }\end{array}$ & $\begin{array}{l}\text { Spanish } \\
\text { names }\end{array}$ & $\begin{array}{l}\text { English } \\
\text { translation }\end{array}$ \\
\hline Abrigo & Coat & Abeja & Bee \\
\hline Anillo & Ring & Ancla & Anchor \\
\hline Armario & Closet & Ardilla & Squirrel \\
\hline Banco & Bench & Bailarina & Dancer \\
\hline Bandera & Flag & Ballena & Whale \\
\hline Barco & Boat & Bate & Bat \\
\hline Bicicleta & Bike & Bombilla & Light Bulb \\
\hline Boca & Mouth & Bota & Boat \\
\hline Botella & Bottle & Bruja & Witch \\
\hline Caballo & Horse & Canguro & Kangaroo \\
\hline Cabra & Goat & Cazo & Pot \\
\hline Cadena & Chin & Cebolla & Onion \\
\hline Caja & Box & Cebra & Zebra \\
\hline Calendario & Calendar & Cereza & Cherry \\
\hline Cama & Bed & Cesta & Basket \\
\hline Camisa & Shirt & Cigarro & Cigarrette \\
\hline Campana & Bell & Cocodrilo & Crocodile \\
\hline Carro & Cart & Cometa & Kite \\
\hline Cerebro & Brain & Conejo & Rabbit \\
\hline Corbata & Tie & Cubo & Bucket \\
\hline Corona & Crown & Cuchara & Spoon \\
\hline Disco & Record & Dedal & Thimble \\
\hline Esqueleto & Skeleton & Elefante & Elephant \\
\hline Falda & Skirt & Faro & Lighthouse \\
\hline Flor & Flower & Fresa & Strawberry \\
\hline Gato & Cat & Gallo & Rooster \\
\hline Globo & Globe & Guante & Glove \\
\hline Huevo & Egg & Hacha & Axe \\
\hline Libro & Book & Lazo & Bow \\
\hline Manzana & Apple & Mariposa & Butterfly \\
\hline Mesa & Table & Martillo & Hammer \\
\hline Muñeca & Doll & Moto & Motorbike \\
\hline Oreja & Ear & Oveja & Sheep \\
\hline Perro & Dog & Pato & Duck \\
\hline Piano & Piano & Peine & Comb \\
\hline Pipa & Pipe & Pera & Pear \\
\hline Pistola & Gun & Piña & Pinneapple \\
\hline Plato & Plate & Pinza & Clothespin \\
\hline Puño & Fist & Pulpo & Octopus \\
\hline Puro & Cigar & Pimiento & Pepper \\
\hline Regalo & Present & Rana & Frog \\
\hline Reloj & Watch & Raqueta & Racket \\
\hline Silla & Chair & Seta & Mushroom \\
\hline Sombrero & Hat & Silbato & Whistle \\
\hline Taza & Mug & Tambor & Drum \\
\hline Tren & Train & Tigre & Tiger \\
\hline Tronco & $\log$ & Tomate & Tomato \\
\hline Zapato & Shoe & Zorro & Fox \\
\hline
\end{tabular}

